\title{
DECLARACIÓN DE GUANAJUATO SOBRE FECUNDACIÓN IN VITRO 20 DE ABRIL DE 2013
}

\section{NotA PREVIA}

En el mes de abril, en la ciudad de Guanajuato, México, se llevó a cabo el IX Congreso de la Federación Latinoamericana y del Caribe de Instituciones de Bioética. Dentro de los temas tratados en dicho evento, de carácter internacional y multidisciplinario, hubo una muy interesante y comentada mesa redonda en relación a la reciente sentencia de la Corte Interamericana de Derechos Humanos en el caso Artavia Murillo y otros vs. Costa Rica, de fecha 28 de noviembre del 2012, con respecto a la aplicación de la Fecundación in Vitro, sesión en la que el Decano de la Facultad de Derecho de la Unifé estuvo presente, a nombre del Instituto de la Familia de la Universidad Femenina del Sagrado Corazón.

Luego de la presentación de las ponencias preparadas para el efecto, se animó un interesante intercambio de ideas -en el que, asimismo, el Decano intervino-, generándose al final del mismo la propuesta de hacer una Declaración con respecto a la referida y polémica decisión.

Al día, siguiente, el 20 de abril, se reunió un importante número de expertos en el área de bioética, incluidos médicos, filósofos, biólogos, juristas, académicos y científicos en general, de diversos países, con el propósito de elaborar y suscribir la "Declaración de Guanajuato", la cual incluye algunas reflexiones interdisciplinarias en relación al citado caso, en cuya resolución se ha incurrido, lamentablemente, en inexactitudes científicas y jurídicas que es importante poner en evidencia para un debido tratamiento de la materia.

Por tratarse de un documento de interés público, de trascendencia no solo jurídica y académica, sino también social, consideramos importante publicarlo en Lumen, revista institucional de la Facultad de Derecho de la Universidad Femenina del Sagrado Corazón, invitando a todas las personas interesadas, a leerla, a fin de conocer su contenido y, de estar conformes con ella, adherirse libremente a la misma, a través de la página: http://www. declaraciondeguanajuato.org/

Nuestra Facultad, vinculada desde hace muchos años en nuestro país al tema de la Bioética, y que ha sido la única en tener a su cargo una Cátedra de Bioética y Biojurídica de la UNESCO, no podía hacer ajena a esta materia, teniendo en cuenta, asimismo, los valores y principios que la inspiran, vinculados con la defensa de la vida, la libertad y los derechos fundamentales de todos los seres humanos.

\section{ANTECEDENTES}

En la Ciudad de Guanajuato, Guanajuato, México el 20 de abril de 2013, se han reunido personas expertas en el área de bioética, incluidos médicos, filósofos, biólogos, juristas, académicos y científicos en general, con el propósito de suscribir la Declaración de Guanajuato que incluye algunas reflexiones interdisciplinarias en relación a la sentencia de la Corte Interamericana de Derechos Humanos en el caso Artavia Murillo y otros
("Fecundación in vitro") vs. Costa Rica del 28 de noviembre de 2012.

\section{Objetivos}

En esta Declaración, se propone evidenciar algunas deficiencias de la sentencia de la Corte Interamericana de Derechos Humanos en el caso ya referido, y postular diversos principios o ideas relevantes que deben considerarse por cualquier órgano nacional o internacional que tenga a su cargo la inter- pretación, promoción y defensa de los derechos humanos. Las personas cuyas firmas aparecen al final de la Declaración ("suscriptores"), aceptan y apoyan cada uno de los puntos enlistados en la misma, y los someten a la comunidad científica internacional para que, quienes coincidan, puedan manifestar su conformidad con ella ("adherentes").

Los suscriptores de la Declaración, lamentamos las imprecisiones científicas y jurídicas 
de la sentencia, por lo que los efectos de la misma deben ser únicamente para el caso planteado, es decir, en virtud de sus deficiencias no puede considerarse como un antecedente legítimo para el tema de la regulación legal de la Fecundación in vitro, ni para algún otro tema relacionado con la misma.

\section{Puntos}

La dignidad humana es el fundamento de los derechos humanos. No existe valor alguno que posea la ultimidad fundamentadora de la dignidad. $\mathrm{Ni}$ siquiera la libertad, la igualdad, o incluso la justicia, son capaces de soportar por sí mismos todo el sistema normativo que suponen los derechos humanos. En consecuencia, todo órgano con funciones judiciales a nivel nacional o internacional, cuando tenga que resolver cuestiones relativas a una posible violación o afectación de derechos humanos, debe acudir ante todo a la dignidad humana, pues es el único elemento del sistema jurídico que le permitirá, por un lado, fundamentar correctamente su resolución en razón del respeto que se debe en todo momento al ser humano y; por otro, orientar la ponderación de derechos, lo cual supone encontrar la mejor manera para ejercitarlos.

La actuación judicial que soslaye la importancia de la dignidad humana y en su lugar coloque algún otro valor o norma, anticipa una solución parcial que lejos de resolver la problemática planteada se traduce en una desprotección del ser humano contrariando la vocación inherente a los derechos humanos.
La vida del embrión humano es, desde el principio humana, pues su naturaleza no se modifica o perfecciona en razón de su crecimiento, desarrollo o suficiencia; en consecuencia, merece desde el principio, la protección que ofrecen los derechos humanos. De la misma manera en que actualmente se reconocen los derechos de los niños, de las mujeres, de las personas con discapacidad, etcétera. Hoy en día los avances científicos en el área de la embriología, nos obligan a plantear y defender los derechos del embrión, colocándose en primer lugar el derecho a la vida dada su condición de vulnerabilidad.

El término “concepción" utilizado por el artículo 4.1 de la Convención Americana de Derechos Humanos, debe ser entendido de la misma manera en que fue considerado al suscribirla en 1969, es decir, como la unión del óvulo con el espermatozoide. El argumento que sostiene que la implantación es lo que define la concepción es falso; la implantación cierra el ciclo de la concepción que, entre otras cosas, permite diagnosticar el embarazo. La práctica misma de las TRHA demuestra que el desarrollo del embrión se inicia desde la fecundación.

Los principales instrumentos internacionales en materia de derechos humanos, tales como: la Declaración Universal de los Derechos Humanos, la Convención Americana de los Derechos Humanos y el Pacto Internacional de los Derechos Civiles y Políticos, establecen expresamente el derecho a la no discriminación, derecho del cual también es titular el embrión; por tanto, no hay razón que justifique la distinción que, en el uso de las Técnicas de Reproducción Humana Asistida (TRHA), se haga entre el embrión cuya implantación se procura y los embriones que son desechados o crioconservados.

Estas acciones las consideramos moralmente reprochables y en las que se necesita una decisiva intervención de las autoridades.

Los derechos humanos son normas independientes, lo cual significa que la legitimidad, existencia, vigencia y pertenencia de cada uno dentro del sistema jurídico no depende de la legitimidad, existencia, vigencia y pertenencia de otro. Por ende, no podemos ni debemos confundir correlación con independencia. De tal modo, que los derechos reproductivos se relacionan, entre otros, con el derecho a la vida privada, pero ello no quiere decir que el primero esté condicionado por el segundo. De no aceptarse, la independencia de los derechos humanos, entonces se tendría que admitir forzosamente la jerarquía entre ellos. Esto es algo que en una sociedad democrática y verdaderamente libre no puede ser aceptado.

El sistema normativo propio de los derechos humanos no admite que uno de ellos, cualquiera que este sea, se sobreponga o imponga a priori a otro, ya que todos tienen la misma jerarquía y la misma fuerza obligatoria. Esto no obsta para que en caso de conflicto se realice una ponderación de los mismos. Considerar el derecho a la vida privada como fundamento de otros derechos como, por ejemplo, los derechos reproductivos no puede 
ser admitido en la lógica planteada.

La historia del mundo contemporáneo bien puede explicarse en términos de una franca lucha entre autoridad y libertad, que ha dado lugar a la irreconciliable división entre vida pública y vida privada como si los derechos humanos pudiesen ubicarse exclusivamente en alguno de esos espacios. La realidad es que los derechos humanos no son exclusivos de la vida pública, así como tampoco son estrictamente de la vida privada. Si los derechos humanos y en especial los derechos reproductivos, estuvieran enraizados únicamente en el ámbito público, estos no serían más que concesiones o prerrogativas que el Estado otorga a las personas. Por el contrario, si estuvieren fincados sólo en el ámbito privado, estos serían una especie de normas o directrices producto de la convención o consenso sociales. Ambas posturas ya están desacreditadas en nuestros días. En consecuencia, todo lo relativo a los derechos humanos, y en particular a los derechos reproductivos, tiene algo de público y algo de privado. Indudablemente en su ejercicio interviene la libertad personal, pero el hecho de que el Estado se preocupe de su reconocimiento, protección y promoción, demuestra que en ellos también hay algo de público, es decir de justicia.

La sociedad espera que cuando un órgano jurisdiccional nacional o internacional asume la protección de los derechos humanos, se allegue de los datos científicos necesarios proporcionados por académicos e investigadores adscritos a universidades y centros de investigación a fin que le permitan una adecuada apreciación de los hechos y circunstancias. En este sentido, se advierten varios errores e imprecisiones científicas y deficiencias metodológicas en la sentencia de la Corte, algunos de los cuales son: a) Peso excesivo de fuentes no científicas para definir la concepción; b) Se afirma de manera incorrecta que: "Antes de la FIV no se contemplaba científicamente la posibilidad de realizar fertilizaciones fuera de la mujer" (No. 179), siendo que desde el año 1934, el Dr. Gregory Pincus lo realizó en conejos; c) Se sostiene que todas las células del embrión de 2 semanas son idénticas (No. 184, pie de página No. 280), cuando en realidad tiene cientos de células y estructuras tan distintas como las membranas placentarias, y las estructuras complejas del embrión ectodermo, endodermo y mesodermo; d) Se confunde al óvulo fecundado con el blastocisto
(No. 180), pues aseguran que el óvulo fecundado es el que se implanta en el endometrio $y$; e) Se afirma que en el embrión en estado de ocho células todas ellas son idénticas (Pag. 59 , cita 280, perito Escalante), cuando es bien sabido que desde el embrión de dos células ya tienen una direccionalidad en donde prioritaria, aunque no únicamente una, define la formación del embrión y la otra célula es la base para la formación de la placenta y membranas placentarias.

La protección mínima que una sociedad justa puede ofrecer a los embriones desde la fecundación es el respeto por los Derechos Humanos. De no ser así, o bien, hacerlo a partir de la implantación daría lugar a acciones reprochables como: el tráfico ilegal de embriones humanos, la compraventa de los mismos o su disposición por los laboratorios sin el permiso de los padres biológicos, ni de los padres adoptivos.

Los suscriptores y adherentes de esta Declaración movidos por nuestra tarea académica y científica de buscar la verdad y realizar el bien en nuestra labor, postulamos estos principios para que orienten toda reflexión que se haga respecto a los derechos humanos $y$, en especial, a los derechos reproductivos. 